\section{Pre- and post-operative management of dental implant placement. Part 1: management of post-operative pain}

\author{
G. Bryce, ${ }^{* 1}$ D. I. Bomfim ${ }^{1}$ and G. S. Bassi ${ }^{1}$
}

VERIFIABLE CPD PAPER
IN BRIEF
- Provides dental practitioners with an overview of the mechanisms of post- operative pain following dental implant placement.
- Discusses the benefits and limitations of commonly employed pain medications for the control of post-operative dental implant pain.
- Provides practical recommendations for the prescription of pain medications post-dental implant placement.

Although dental implant placements have high success rates and a low incidence of morbidity, post-operative pain and complications with the healing process have been reported. There is little guidance available regarding optimal pre- and postoperative management of dental implant placement. This first paper discusses the mechanisms of pain associated with dental implant placement and offers guidance to clinicians on optimal pre- and post-operative pain management regimes. The second paper aims to discuss pre- and post-operative means of reducing the risk of early healing complications.

\section{INTRODUCTION}

It is well recognised that high success rates $^{1}$ and levels of patient satisfaction ${ }^{2}$ can be achieved with dental implants if sound pre-operative assessment/planning is adopted and an exacting surgical technique employed. ${ }^{3}$ Surprisingly, there is limited information available about the role that pre- and post-operative medication plays on treatment outcome and patient experience.

Certain aspects of patient management, generally relating to the prophylactic prescription of antibiotics as a preventative measure against infective endocarditis, have been reported on and feature within both Governmental (National Institute for Health and Care Excellence) and independent body (Royal College of Surgeons of England) guidelines. However, these bodies do not provide similar levels of evidence-based guidance for the use of pre- and post-operative management to improve outcome for patients receiving dental implant placement.

The aim of this two-part series is to update clinicians on current aspects of pre- and post-operative care associated with dental implant placement. In this first paper, the means of managing post-operative pain will be reviewed and recommendations made. Part two will aim to discuss aspects of preand post-operative patient management

'Restorative Department, Eastman Dental Hospital, 256 Gray's Inn Road, London, WC1X 8LD

${ }^{*}$ Correspondence to: Graeme Bryce

Email: graemebryce001@hotmail.com

\section{Refereed Paper}

Accepted 17 April 2014

DOI: $10.1038 /$ sj.bdj.2014.650

${ }^{\circledR}$ British Dental Journal 2014; 217: 123-127 that can be employed to optimise the healing process and reduce post-operative complications.

\section{THE MECHANISM OF OROFACIAL PAIN}

Post-operative pain is an unfortunate consequence of the unavoidable tissue damage that occurs following the surgical placement of dental implants. Pain has been defined as an 'unpleasant sensory and emotional experience associated with actual or potential tissue damage. ${ }^{4}$ The sensation of pain may result from both the initial surgical insult and the subsequent inflammatory process. The surgical insult breaches the threshold of nociceptors located within both the periodontal and osseous tissues and mediates an acute pain sensation via fast signal-speed myelinated A-delta fibres (signal speed of $5-30 \mathrm{~m} / \mathrm{s}$ ). This signal is transmitted, via the dorsal horn of the spinal cord, to higher central nervous system (CNS) centres, where pain is perceived. Inflammatory pain is normally characterised as dull or throbbing in nature and is regulated by the activation of slower signal-speed unmyelinated $C$ fibres (signal speed of $0.5-2 \mathrm{~m} / \mathrm{s}$ ). It is reported that inflammatory pain reaches its zenith at approximately 48-72 hours post-surgery ${ }^{5}$ and is guided by the release of inflammatory mediators. These inflammatory mediators can either act directly on peripheral nociceptors (for example, bradykinin ions [potassium, hydrogen], histamine and nitric oxide), resulting in spontaneous pain, or indirectly (growth factors, neuropeptides such as substance $P$ and calcitonin gene-related peptide) by stimulating the release of pain-inducing factors from recruited inflammatory cells. In addition, some factors, such as cytokines, leukotrienes and prostaglandins (via activation of the arachidonic acid pathway), are capable of both direct and indirect nociceptor stimulation (Fig. 1).

\section{POST-IMPLANT PLACEMENT PAIN}

Although it is accepted that the majority of patients will experience mild to moderate pain following dental implant placement, ${ }^{6}$ the exact role that general and specific factors play in this process is poorly understood. General patient factors such as gender, anxiety levels ${ }^{6,7}$ and smoking status $^{5}$ have been implicated in exacerbating post-operative pain perception. Additional factors, specific to the surgical placement of implants, which are likely to increase postoperative pain include: grafting techniques, ${ }^{8}$ number of implants placed, ${ }^{8}$ posterior siting of implant (possibly due to greater extension of the surgical flap), ${ }^{8}$ excessive heat generation resulting from inadequate cooling of the surgical bur/osseous interface, ${ }^{9}$ extensive surgical flaps, poor flap management and over-torquing of the implant (Table 1).

Pain medications can reduce post-operative discomfort by depressing the nociceptive system, either within the central nervous system or on the peripheral nerve terminals. Those medications that can be used to manage pain subsequent to dental surgery, include:

1. Non-steroidal anti-inflammatories

(NSAIDs) - non-specific and

cyclooxygenase (COX)-specific

2. Paracetamol

3. Opioids

4. Corticosteroids. 
Little research has been applied to the investigation of the efficacy of oral analgesics in the management of post-implant placement pain. In contrast, the greater proportion of studies has investigated the effectiveness of different analgesics in the management of post-operative pain, using an established third-molar extraction model. ${ }^{10}$ Although there are obvious differences between the extraction of a tooth and the placement of a dental implant, the mucosal and alveolar tissues are traumatised in both procedures, resulting in similar mechanisms of inflammatory pain. By examining the existing literature on the use of analgesics in the management of postextraction pain, tentative conclusions can be drawn regarding their efficacy as postoperative analgesics for implant procedures.

\section{NSAIDS}

Given the known role that prostaglandins play in both the inflammatory and pain pathways, it is unsurprising that NSAIDs hold prominent standing within dentists' post-operative prescription armamentarium. This class of drug exerts an analgesic effect by inhibiting the action of one or both isoenzymes of the cyclooxygenase enzymes, COX-1 and COX-2, resulting in decreased production of pain-mediating prostaglandins and thromboxane. However, while the inhibition of COX-2 is paramount to pain reduction, COX-1 plays an important role within homeostatic function and its inhibition can produce unwanted side-effects such as alterations in the functions of the stomach mucosal lining and decreased platelet coaggregation. These drugs can also significantly affect the action of other medication such as the anticoagulant, warfarin.

Although there are approximately 20 different types of NSAIDs available for prescription in the British National Formulary (and many more outside the formulary), the most extensively evaluated have been the non-selective COX inhibitors: aspirin, ibuprofen and diclofenac.

A meta-analysis assessing the efficacy of commonly provided analgesics found that $800 \mathrm{mg}$ ibuprofen prescribed 6-8 hourly offered the most effective pain relief. ${ }^{11}$ However, the dose-effectiveness relationship that relates to the prescription of ibuprofen also incurs the increased risks of adverse side effects. In general, effective analgesia is achieved with $400-600 \mathrm{mg}$ of ibuprofen administered every 4-6 hours, but not exceeding $2,400 \mathrm{mg}$ in a 24 hour period. ${ }^{11}$ The analgesic efficacy of diclofenac is similar to that of ibuprofen and effective pain relief is reported with 50 and $100 \mathrm{mg}$ of diclofenac taken every 4-6 hours. ${ }^{12}$ There is evidence to

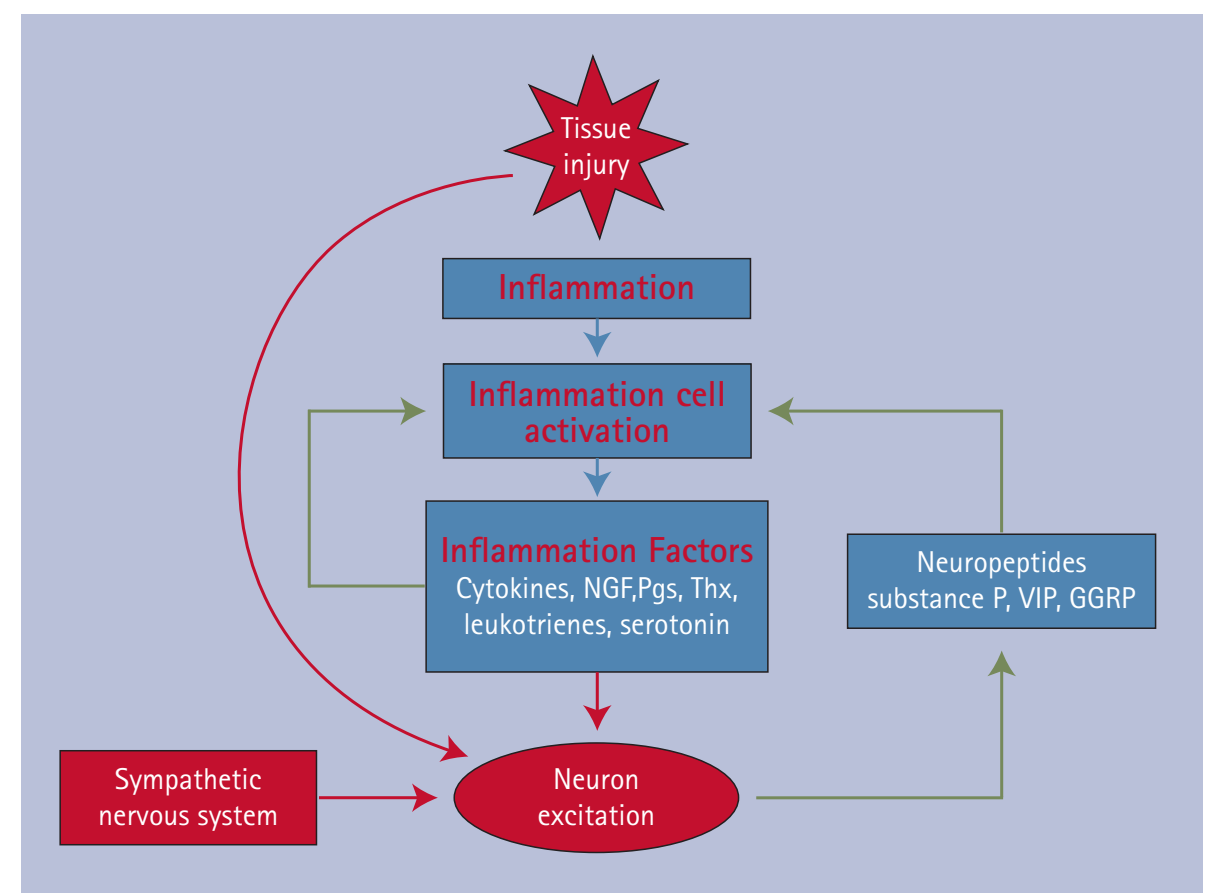

Fig. 1 An overview diagram, simplifying the mechanism of inflammatory pain

Table 1 Post-operative pain related to general and site-specific factors

\begin{tabular}{l|l}
\hline General factors & Site specific \\
\hline Gender (increased pain reported by females) & Increased numbers of implants \\
\hline High anxiety levels & Placement within posterior regions \\
\hline Smoking habits & Use of grafting techniques \\
\hline & Extent of flap \\
\hline & Operator technique \\
\hline & Heat generation at surgical site
\end{tabular}

suggest that longer-term dosing of ibuprofen is associated with reduced gastric side effects than diclofenac ${ }^{13}$ and may also lead to severe complications within asthmatic patients. ${ }^{14}$ Both ibuprofen and diclofenac have been reported to offer more effective pain relief than aspirin.

To combat some of the unwanted effects of non-selective COX inhibition, selective(for example, rofecoxib and NS-389) and preferential COX-2 inhibitors (for example, etodolac, meloxicam, nimesulide, celecoxib) have been developed. Selective COX-2 inhibitors have also been shown to have minimal impact on platelet coaggregation or the anticoagulant effect of warfarin, in contrast to their non-selective counterparts. ${ }^{15}$ However, there has been controversy regarding selective COX-2 inhibitors and their use has been implicated with the increased risk of myocardial infarction. It is also worth considering that selective COX-2 inhibitors have not been shown to have greater pain-relieving efficacy than their non-selective counterparts and their gastric-protective advantages are likely to be limited, given the short dosing-duration that could be expected in the management of post-implant placement pain. Given the aforementioned limitations and the considerable increased cost associated with their prescription, the use of COXselective inhibitors is probably not justified for routine post-operative implant treatment and should be reserved for those where other medications are contra-indicated, such as patients suffering from chronic gastric conditions or asthma.

It is important to recognise that, although appropriate analgesia is crucial, management of post-operative pain should not be at the expense of either healing- or osseointegration- processes. While the inhibition of prostaglandins by NSAIDs may have useful anti-inflammatory effects, such as reducing swelling, it also poses a potentially detrimental effect on bone metabolism by impairing angiogenesis and osteoblast/osteoclast pre-cursor differentiation. Presently, there is still uncertainty regarding the extent to which NSAIDs interfere with the osseointegration process and this warrants consideration, if such drugs are 
to be prescribed following dental implant placement. The interpretation of results from animal-based studies are inconclusive with some studies indicating that the use of selective and non-selective NSAIDs may affect osseointegration, particularly within the 21-28 day healing period, ${ }^{16-19}$ while other studies found no difference in longer-term healing outcomes. ${ }^{20}$ The use of flubriprofen, a non-selective COX inhibitor, has been demonstrated to improve peri-implant bone deposition ${ }^{21,22}$ but these findings are unsupported by longer term clinical trials. Despite ongoing research within this field, it is still unclear whether short courses of NSAIDs, required for postoperative management, have a clinically relevant detrimental impact on implant osseointegration. Subsequently, no direct contraindicating advice can be given for the short-term prescription of such medications for the management of post-operative pain.

\section{PARACETAMOL}

Paracetamol exerts only a weak antiinflammatory effect and is not considered to be a member of the NSAID family. The exact mechanism of action of paracetamol is poorly understood but it is believed to act both peripherally, via inhibition of the COX-2 enzyme, and also centrally, by inhibiting the reuptake of endogenous cannabinoid anandamide within sensory neurons. As regards the latter process, inhibited anandamide reuptake results in lower synaptic levels and reduced nociceptor activation. Either of these inhibitions by themselves has been shown to reduce pain but it has been demonstrated that paracetamol's analgesic effects are inhibited following the blocking of cannabinoid receptors with synthetic antagonists, suggesting that this is the drug's primary mode of action.

Although ibuprofen is generally regarded as a more effective analgesic, ${ }^{23}$ paracetamol still has good pain-relieving properties and also fewer reported side effects. It is relevant that paracetamol has reduced impact on prostaglandin production and, therefore, poses less risk to the osseointegration process. The therapeutic dose of paracetamol has been established at approximately $1,000 \mathrm{mg}$ to be taken every four hours with the maximum dose not to exceed $4,000 \mathrm{mg}$ in a 24 -hour period. ${ }^{24}$ Patients should also be warned about the risk of hepatic failure in cases of overdose.

The combined use of NSAIDs and paracetamol has been demonstrated to have a synergistic effect on the management of post-operative dental pain ${ }^{25}$ and combined regimes of these drugs should be considered if severe post-implant pain is anticipated.
There is no evidence to suggest that combining NSAIDs and paracetamol has an antagonistic action on osseointegration.

\section{OPIOIDS}

Painful stimuli are transmitted to the medullary region of the central nervous system via A-delta and C fibres within the trigeminal nerve. Subsequent regulation of this painful response is via a family of endogenous opioid peptides (metencephalon, dynorphin, beta-endorphin) that act on opiate receptors to suppress pain. Four types of opiate receptor have been categorised: mu, kappa, sigma and delta. The activation of mu and kappa receptors results in analgesia but can also cause euphoria and respiratory depression. Other unwanted side-effects such as constipation (sigma receptor activation) and altered behaviour (delta receptor activation) can also result from the administration of opioids. Although unlikely to be a factor within the shorter term management of post-implant pain, prolonged use of opiates is associated with increased risk of dependence and desensitisation of opioid receptors that can, in turn, reduce the pain-relieving effectiveness of these drugs.

Codeine (3-methylmorphine) is a member of the opiate family and its potency is one sixth of that of morphine. Codeine's mechanism of action is via the activation of opioid receptors. Codeine, as a sole drug, can be prescribed at strengths of $8,15,30$ or $60 \mathrm{mg}$ four times daily with a maximum dose of $360 \mathrm{mg}$ in a 24-hour period. However, its pain-relieving effectiveness, when prescribed as a sole analgesic, is disputed with studies showing only minimal benefit for post-operative pain. ${ }^{26}$ The side effects associated with codeine are dose related and include nausea, constipation and drowsiness. ${ }^{23}$ It is advised that the prescription of Codeine is combined with either paracetamol (in ratios of 8/500, $12 / 500$ or $30 / 500 \mathrm{mg}$ ) or ibuprofen (in ratios of $12 / 400$ ) where it has a synergistic impact on relieving post-operative pain. . $^{23,27,28}$

Tramadol is a synthetic analogue of codeine but has a reduced affinity for $\mu$-opioid receptors while also having an action on 5-hydroxytryptamine-noradrenaline reuptake inhibitors (SNRIs). ${ }^{29}$ Like codeine, its analgesic efficacy is improved when prescribed in combination with paracetamol. ${ }^{15}$ However, greater side effects associated with its use are reported and include: constipation, anxiety, seizure, tolerance and dependence. Although its use for post-operative dental pain is common within the United States, the drug courts controversy regarding the severity of its side effects. In the UK tramadol is not commonly prescribed for dental pain.

\section{CORTICOSTEROIDS}

Synthetic glucocorticosteroids are the primary type of corticosteroids that can be used to inhibit both immune and inflammatory responses. Glucocorticosteroids inhibit inflammatory pathways at multiple levels and their full mechanism of action is out with the realms of this paper. To summarise, the scope of glucocorticoid action is far less selective than that of NSAIDs and they inhibit the vascular and cellular inflammatory responses at multiple levels, in addition to impacting on the immune system (via inhibition of cytokine production). The analgesic effects exerted by the use of corticosteroids result from the inhibition of prostaglandins,$^{30}$ in a manner that is similar to that of NSAIDs. Corticosteroids such as cortisol, prednisolone and dexamethasone ${ }^{31}$ can be effectively used in the management of post-operative pain in fields such as endodontics and oral surgery. However, glucocorticosteroids have a profound action on osteoblast precursor cells ${ }^{22,32}$ and their use has been shown to reduce osteoblast adhesion to the implant surface, ${ }^{33}$ therefore potentially compromising osseointegration. It can therefore not be recommended for post-operative implant pain management.

\section{ADJUNCTS TO POST-OPERATIVE ANALGESIA}

The use of prophylactic or single-dose analgesics, before the surgical procedure, to manage post-operative pain has been investigated but with inconclusive results. Ibuprofen, paracetamol (with or without codeine) and diclofenac taken prophylactically can reduce perceived pain in the immediate post-operative aftermath. ${ }^{34}$ Similarly, post-operative single doses of ibuprofen or diclofenac have achieved 50\% pain relief in one third of patients. However, single dose analgesics are rarely successful in achieving complete post-operative pain control and many patients will ultimately seek 'rescue' analgesics to mediate discomfort. The provision of single dose prophylactic- or post-operative analgesic does not serve as a predictable method of managing post-operative pain ${ }^{35,36}$ and it is advised that this form of medication should be seen as an adjunct to a more comprehensive post-operative analgesic regime.

Long acting local anaesthetics, such as bupivacaine, have also been recommended as a useful adjunct for the management of immediate post-operative pain. ${ }^{37}$ They can provide up to eight hours of analgesia, affording the patient with ample time to commence their post-operative analgesic regime. However, prolonged anaesthesia of the oral tissues can interfere with function and may 
also increase the risk of soft tissue trauma through accidental cheek or lip biting. These factors should be taken into consideration, if a long-acting local anaesthetic is to be used.

The use of alternative therapies for management of post-operative pain has been studied with techniques such as acupuncture, ${ }^{38}$ electro-acupuncture, ${ }^{39}$ traditional Chinese medicines, homeopathy (such as arnica) and herbal remedies, having been investigated. Much of the available evidence is of low quality and care should be taken if adopting such an approach for management of post-operative pain subsequent to implant placement.

\section{CONCLUSION}

A degree of post-operative pain can be expected following dental implant surgery and it is crucial that the clinician provides effective analgesia without compromising either healing or osseointegration of the dental implant. Table 2 summarises the advantages and disadvantages of each group of analgesics. Despite the undisputed analgesic efficacy of NSAIDs for managing post-surgical dental pain, there lies potential for these drugs to interfere with the healing/osseointegration process. Given this risk, it would therefore seem sensible to consider alternatives to the prescription of NSAIDs. The prescription of $1 \mathrm{~g}$ paracetamol four times daily has been shown to be effective when compared to NSAIDs, while incurring less risk to the osseointegration process. Paracetamol should therefore be considered as a first line post-operative analgesic. Enhanced analgesia can be obtained with the addition of codeine although, due to variable individual tolerances, codeine dosage should be assessed on a case-bycase basis. While $60 \mathrm{mg}$ codeine combined with paracetamol four times daily offers optimal pain relief, this regime must be weighed against the potential for increased side effects. If in doubt, a reduced dosage of codeine should be adopted. Finally, further research is needed to evaluate the risk to the osseointegration process posed by commonly prescribed analgesics.

1. Roos J, Sennerby L, Lekholm U, Jemt T, Gröndahl K, Albrektsson T. A qualitative and quantitative method for evaluating implant success: a 5-year retrospective analysis of the Branemark implant. Int J Oral Maxillofac Implants 1997; 12: 504-514.

2. Pjetursson B E, Karoussis I, Bürgin W, Brägger $U$, Lang N P. Patients' satisfaction following implant therapy. A 10-year prospective cohort study. Clin Oral Implants Res 2005; 16: 185-193.

3. Albrektsson T, Zarb G, Worthington P, Eriksson A R. The long-term efficacy of currently used dental implants: a review and proposed criteria of success. Int J Oral Maxillofac Implants 1986; 1: 11-25.

4. International Association for the Study of Pain. Pain terms: a list with definitions and notes on usage. Recommended by the IASP Subcommittee on

Table 2 Summary of advantages/disadvantages associated with commonly employed analgesics in dental implant placement

\begin{tabular}{|c|c|c|}
\hline Medication & Advantages & Disadvantages \\
\hline $\begin{array}{l}\text { NSAIDs } \\
\text { Non-selective } \\
\text { COX selective }\end{array}$ & $\begin{array}{l}\text { Excellent pain relief } \\
\text { Beneficial anti-inflammatory effects } \\
\text { Cheap } \\
\text { Excellent pain relief }\end{array}$ & $\begin{array}{l}\text { Uncertain impact on } \\
\text { osseointegration process } \\
\text { Drug interactions } \\
\text { Limited use in patients' suffering gastric } \\
\text { conditions and asthmatics } \\
\text { Expensive } \\
\text { Concerns over side-effects }\end{array}$ \\
\hline Paracetamol & $\begin{array}{l}\text { Excellent pain relief } \\
\text { Minimal impact on } \\
\text { osseointegration process } \\
\text { Inexpensive }\end{array}$ & No anti-inflammatory effects \\
\hline Opioids & Good pain relief & $\begin{array}{l}\text { Addiction } \\
\text { No anti-inflammatory effects }\end{array}$ \\
\hline Corticosteroids & Anti-inflammatory action & $\begin{array}{l}\text { Non-selective inhibition of } \\
\text { inflammatory response } \\
\text { Reduction of osteoblast adhesion } \\
\text { with potential compromise of } \\
\text { osseointegration process }\end{array}$ \\
\hline
\end{tabular}

Taxonomy. Pain 1979: 6: 249.

Urban T, Wenzel A. Discomfort experienced after immediate implant placement associated with three different regenerative techniques. Clin Oral Implants Res 2010; 21: 1271-1277

6. Hashem A A, Claffey N M, O'Connell B. Pain and anxiety following the placement of dental implants. Int J Oral Maxillofac Implants 2006; 21: 943-950.

7. Eli I, Schwartz-Arad D, Baht R, Ben-Tuvim H. Effect of anxiety on the experience of pain in implant insertion. Clin Oral Implants Res 2003; 14: 115-118.

8. Gonzalez-Santana H, Penarrocha-Diago M, Guarinos-Carbo J, Balaguer-Martinez J. Pain and inflammation in 41 patients following the placement of 131 dental implants. Med Oral Patol Oral Cir Bucal 2005; 10: 258-263.

9. Eriksson R A, Albrektsson T. The effect of heat on bone regeneration: An experimental study in the rabbit using the bone growth chamber. J Oral Maxillofac Surg 1984; 42: 705-711.

10. Cooper S A, Beaver W T. A model to evaluate mild analgesics in oral surgery outpatients. Clin Pharmacol Ther 1976; 20: 241-250.

11. Albrektsson T, Brånemark P I, Hansson $\mathrm{H}_{\mathrm{A}}$, Lindström J. Osseointegrated titanium implants: Requirements for ensuring a long-lasting, direct bone-to-implant anchorage in man. Acta Orthopaedica 1981; 52: 155-170.

12. Collins S L, Moore R A, McQuay H J, Wiffen P J. Ora ibuprofen and diclofenac in post-operative pain: a quantitative systematic review. Eur J Pain 1998; 2: 285-291.

13. Henry D, Lim L L, Garcia Rodriguez L A et al. Variability in risk of gastrointestinal complications with individual non-steroidal anti-inflammatory drugs: results of a collaborative meta-analysis. BrMed J 1996; 312: 1563-1566.

14. Levy $S$, Volans $G$. The use of analgesics in patients with asthma. Drug Saf 2001; 24: 829-841.

15. Medve R A, Wang J, Karim R. Tramadol and acetaminophen tablets for dental pain. Anesth Prog 2001; 48: 79-81.

16. Trancik T, Mills W, Vinson N. The effect of indomethacin, aspirin, and ibuprofen on bone ingrowth into a porous-coated implant. Clin Orthop Relat Res 1989; 249: 113-121.

17. Guida L, Annunziata M, Passaro I et al. Acetylsalicylic acid inhibits proliferation of human bone marrow stromal cells and matrix mineralization. Int $\mathrm{J}$ Immunopathol Pharmacol 2008; 21: 921-928.

18. Pablos A B, Ramalho S A, Konig B Jr et al. Effect of meloxicam and diclofenac sodium on peri-implant bone healing in rats. J Periodonto/ 2008; 79: 300-306.

19. Ribeiro FV, Cesar-Neto J B, Nociti F H Jr et al. Selective cyclooxygenase-2 inhibitor may impair bone healing around titanium implants in rats. $J$
Periodontol 2006: 77: 1731-1735.

20. Alissa R, Sakka S, Oliver R et al. Influence of ibuprofen on bone healing around dental implants: a randomised double-blind placebo-controlled clinical study. Eur J Oral Implantol 2009; 2: 185-199.

21. Jeffcoat M K, Reddy M S, Wang I C et al. The effect of systemic flurbiprofen on bone supporting dental implants. J Am Dent Assoc 1995; 126: 305-311.

22. Walsh $S$, Jordan $G R$, Jefferiss $C$, Stewart $K$, Beresford $J$ N. High concentrations of dexamethasone suppress the proliferation but not the differentiation or further maturation of human osteoblast precursors in vitro: relevance to glucocorticoid-induced osteoporosis. Rheumatology (Oxford) 2001; 40: 74-83.

23. McQuay H J, Carroll D, Guest P, Juniper R P, Moore $R$ A. A multiple dose comparison of combinations of ibuprofen and codeine and paracetamol, codeine and caffeine after third molar surgery. Anaesthesia 1992; 47: 672-677

24. Barden J, Edwards J E, McQuay H J, Moore A R. Pain and analgesic response after third molar extraction and other postsurgical pain. Pain 2004: 107: 86-90

25. Mehlisch D R. The efficacy of combination analgesic therapy in relieving dental pain. J Am Dent Assoc 2002: 133: 861-871.

26. Bandolier. Oxford league table of analgesics. Bandolier. 2007. Online table available at http:// www.medicine.ox.ac.uk/bandolier/booth/painpag/ Acutrev/Analgesics/Leagtab.html (accessed May 2014).

27. Breivik E K, Barkvoll P, Skovlund E. Combining diclofenac with acetaminophen or acetaminophencodeine after oral surgery: a randomized, doubleblind single-dose study. Clin Pharmacol Ther 1999; 66: 625-635.

28. Mehlisch D R, Aspley S, Daniels S E, Southerden K A, Christensen K S. A single-tablet fixed-dose combination of racaemic ibuprofen/paracetamol in the management of moderate to severe postoperative dental pain in adult and adolescent patients: a multicentre, two-stage, randomized, double-blind, parallel-group, placebo-controlled, factorial study. Clin Ther 2010; 32: 1033-1049.

29. Lewis K S, Han N H. Tramadol: a new centrally acting analgesic. Am J Health Syst Pharm 1997; 54: 643-652.

30. Olstad O A, Skjelbred P. Comparison of the analgesic effect of a corticosteroid and paracetamol in patients with pain after oral surgery. Br J Clin Pharmacol 1986; 22: 437-442.

31. Chopra D, Rehan H S, Mehra P, Kakkar A K. A randomized, double-blind, placebo-controlled study comparing the efficacy and safety of paracetamol, serratiopeptidase, ibuprofen and betamethasone using the dental impaction pain model. Int J Oral Maxillofac Surg 2009; 38: 350-355.

32. Scutt $A$, Bertram $P$, Brautigam M. The role of 
glucocorticoids and prostaglandin E2 in the recruitment of bone marrow mesenchymal cells to the osteoblastic lineage: positive and negative effects. Calcif Tissue Int 1996; 59: 154-162.

33. Cho P, Schneider G B, Kellogg B, Zaharias R, Keller J C. Effect of glucocorticoid-induced osteoporoticlike conditions on osteoblast cell attachment to implant surface microtopographies. Implant Dent 2006; 15: 377-385.

34. Joshi A, Parara E, Macfarlane T V. A double-blind randomised controlled clinical trial of the effect of preoperative ibuprofen, diclofenac, paracetamol with codeine and placebo tablets for relief of postoperative pain after removal of impacted third molars. Br J Oral Maxillofac Surg 2004; 42: 299-306.

35. Gustafsson I, Nystrom E, Quiding H. Effect of preoperative paracetamol on pain after oral surgery. Eur J Clin Pharmacol 1983; 24: 63-65.

36. Bridgman J B, Gillgrass T G, Zacharias M. The absence of any pre-emptive analgesic effect for non-steroidal anti-inflammatory drugs. Br J Oral Maxillofac Surg 1996; 34: 428-431.

37. Rosenquist J B, Rosenquist K I, Lee P K. Comparison between lidocaine and bupivacaine as local anaesthetics with diflunisal for postoperative pain control after lower third molar surgery. Anesth Prog 1988; 35: 1-4.

38. Lao L, Bergman S, Langenberg P, Wong R H, Berman B. Efficacy of Chinese acupuncture on postoperative oral surgery pain. Oral Surg Oral Med Oral Pathol Oral Radiol Endod 1995; 79: 423-428.

39. Sung Y F, Kutner M H, Cerine F C, Frederickson E L. Comparison of the effects of acupuncture and codeine on postoperative dental pain. Anesth Analg 1977; 56: 473-478 